\title{
Adult Respiratory Distress Syndrome with Increased Serum and Bronchoalveolar Lavage Fluid Levels of Squamous Cell Carcinoma-Related Antigen
}

\author{
Jun-ichi Ashitani, Hiroshi Mukae, Hirotoshi Ihiboshi, \\ Haruko TAniguchi, Hideo Mashimoto and Shigeru MatsukURA
}

\begin{abstract}
We report a case with adult respiratory distress syndrome (ARDS) associated with increased levels of squamous cell carcinoma-related antigen (SCC) in the serum and bronchoalveolar lavage fluid (BALF). ARDS was likely induced by ibuprofen, based on the presence of pancytopenia and a weakly positive drug lymphocyte stimulating test (DLST). High serum and BALF levels of interleukin (IL)-8, neutrophil elastase as well as SCC were detected. Corticosteroid therapy resulted in clinical improvement, resolution of pulmonary infiltrates on chest roentgenogram and normalization of serum and BALF levels of IL-8, neutrophil elastase and SCC. (Internal Medicine 35: 497-501, 1996)
\end{abstract}

Key words: adult respiratory distress -syndrome (ARDS), neutrophil elastase, squamous cell carcinoma-related antigen (SCC), interleukin (IL)-8

\section{Introduction}

Adult respiratory distress syndrome (ARDS) is a clinical entity characterized by severe dyspnea, hypoxemia and diffuse bilateral pulmonary infiltrates without cardiac failure. It is well known that neutrophils, neutrophil elastase and mononuclear cell-related cytokines such as tumor necrosis factor $\alpha$ (TNF $\alpha)$ and interleukin (IL)-1 $\beta$ are implicated in the pathophysiology of ARDS (1).

The squamous cell carcinoma-related antigen (SCC) is a typical tumor marker for squamous cell carcinoma, and is elevated in several types of malignancies. However, serum levels of SCC have also been reported to be elevated in nonmalignant disease $(2,3)$. Furthermore, mononuclear cell-related cytokines can stimulate the production of SCC antigen from normal squamous epithelium (4).

We present a case of ARDS, probably induced by ibuprofen, with increased serum and bronchoalveolar lavage fluid (BALF) levels of SCC. In addition, elevated serum and BALF levels of IL-8 and neutrophil products such as neutrophil elastase and defensins (5) were also detected in this patient.

\section{Case Report}

A 62-year-old man (height: $165 \mathrm{~cm}$, weight: $55 \mathrm{~kg}$ ), a habitual smoker, was admitted to our hospital because of dyspnea and fever. One week prior to admission he complained of productive cough which was treated with ibuprofen and lysozyme at a private clinic. However, fever and severe dyspnea developed within the following week. At that stage, hypoxemia and diffuse reticulonodular shadows were noted on the chest $X$ ray, bilaterally. He was referred to our hospital for further examination and treatment.

On admission, he had fever (body temperature $38.0^{\circ} \mathrm{C}$ ), tachycardia (pulse rate 188 beats/min), with blood pressure of $110 / 72 \mathrm{mmHg}$. Clinical examination revealed anemia and the presence of bilateral fine crackles at the lower regions of the back of the chest. The central venous pressure was $5 \mathrm{cmH}_{2} \mathrm{O}$. His past and family histories were unremarkable including drug allergy.

The results of laboratory tests on admission showed pancytopenia with white blood cell count of $1,500 / \mathrm{mm}^{3}(68 \%$ neutrophils, Table 1), red blood cell count of $235 \times 10^{4} / \mathrm{mm}^{3}$ and platelet count of $5.8 \times 10^{4} / \mathrm{mm}^{3}$. Biochemical tests revealed hypoproteinemia (total protein $4.37 \mathrm{~g} / \mathrm{dl}$ and albumin $1.79 \mathrm{~g} /$ dl), mild liver dysfunction (GOT $95 \mathrm{IU} / l$ and GPT $115 \mathrm{IU} / l$ ), and

From the Third Department of Internal Medicine, Miyazaki Medical College, 5200 Kiyotake-cho, Kihara, Miyazaki 889-16

Received for publication September 11, 1995; Accepted for publication May 8, 1996

Reprint requests should be addressed to Dr. Jun-ichi Ashitani, the Third Department of Internal Medicine, Miyazaki Medical College, 5200 Kiyotake-cho, Kihara, Miyazaki 889-16 
Table 1. BALF Findings and Levels of SCC and NeutrophilRelated Mediators

\begin{tabular}{|c|c|c|}
\hline & before therapy & $\begin{array}{l}\text { one month } \\
\text { after therapy }\end{array}$ \\
\hline $\mathrm{WBC}\left(/ \mathrm{mm}^{3}\right)$ & 1,500 & 7,800 \\
\hline Neutrophil (\%) & 68 & 64 \\
\hline \multicolumn{3}{|l|}{ BALF } \\
\hline Recovery rate (\%) & 32 & 43 \\
\hline Cell counts $\left(\times 10^{5} / \mathrm{ml}\right)$ & 1.11 & 1.16 \\
\hline Neutrophil (\%) & 65 & 2 \\
\hline $\mathrm{AM}(\%)$ & 25 & 93 \\
\hline Lymphocyte (\%) & 10 & 5 \\
\hline OKT4/8 & 0.5 & N.P. \\
\hline Albumin (mg/dl) & 4.5 & 0.7 \\
\hline \multicolumn{3}{|l|}{ Neutrophil } \\
\hline \multicolumn{3}{|l|}{ Elastase } \\
\hline Plasma $(16-45 \mu \mathrm{g} / l)^{*}$ & 149 & N.P. \\
\hline $\operatorname{BALF}(<10 \mu \mathrm{g} / l, \mathrm{n}=7)^{*}$ & 360 & 16 \\
\hline \multicolumn{3}{|l|}{ IL-8 } \\
\hline Serum $(2.5 \pm 5.6 \mathrm{pg} / \mathrm{ml}, \mathrm{n}=7)^{*}$ & 413.6 & 23.0 \\
\hline $\operatorname{BALF}(21 \pm 46 \mathrm{pg} / \mathrm{ml}, \mathrm{n}=7)^{*}$ & 1,804 & 24.8 \\
\hline \multicolumn{3}{|l|}{ Defensins } \\
\hline Plasma (254.8 $\pm 66.3 \mathrm{pg} / \mu \mathrm{l}, \mathrm{n}=12)^{*}$ & $4,109.4$ & 151.0 \\
\hline BALF (16.1 $\pm 15.2 \mathrm{pg} / \mu \mathrm{l}, \mathrm{n}=12)^{*}$ & $3,008.0$ & 86.0 \\
\hline \multicolumn{3}{|l|}{$\mathrm{SCC}$} \\
\hline Serum $(<1.5 \mathrm{ng} / \mathrm{ml})^{*}$ & 29.5 & $<1$ \\
\hline $\operatorname{BALF}(5.3 \pm 1.1 \mathrm{ng} / \mathrm{ml}, \mathrm{n}=3) *$ & 111 & 6.7 \\
\hline
\end{tabular}

WBC: white blood cell, BALF: bronchoalveolar lavage fluid, AM: alveolar macrophages, N.P.: not performed, SCC: squamous cell carcinoma-related antigen.

Normal levels of serum SCC described in ref. $(14,15)$. *Numbers in parentheses refer to average in healthy volunteers.

increased serum levels of LDH (792 IU/l) and C-reactive protein $(34.5 \mathrm{mg} / \mathrm{dl})$. Elevation of the erythrocyte sedimentation rate $(135 \mathrm{~mm} / \mathrm{hr})$ and negative blood culture were also observed. Both anti-mycoplasma and anti-chlamydia antibodies were negative. Analysis of arterial blood gases during oxygen therapy $\left(10 \mathrm{l} / \mathrm{min}\right.$ ) showed $\mathrm{PaO}_{2}$ of 49 Torr, $\mathrm{PaCO}_{2}$ of 31 Torr and $\mathrm{pH}$ of 7.46. The titers of antibodies against influenza, parainfluenza virus, adenovirus and respiratory syncytial virus revealed no evidence of viral infections. The drug lymphocyte stimulation test (DLST) against ibuprofen was weakly positive (stimulation index 187\%). The serum SCC, which is one of the markers for malignancies followed by immunosuppressive state and opportunistic infection, was markedly elevated $(29.5 \mathrm{ng} / \mathrm{ml})$. Chest roentgenogram (Fig. 1) and computed tomography scan (Fig. 2) demonstrated diffuse reticulonodular shadows and infiltrates without masses in both lungs. Cervical and abdominal examination revealed no malignancy.

On the day of admission, bronchoalveolar lavage was performed using a standard precedure described previously (6) after intubation. A sample of BALF from the right $\mathrm{B}^{5}$ showed

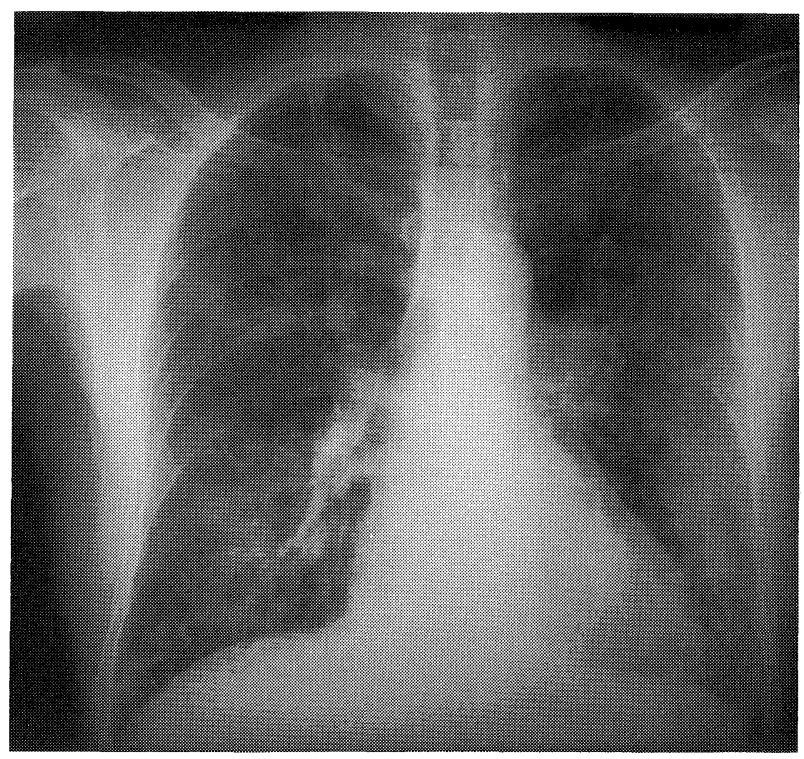

Figure 1. Chest roentgenogram on admission showing bilateral diffuse reticulonodular shadows.

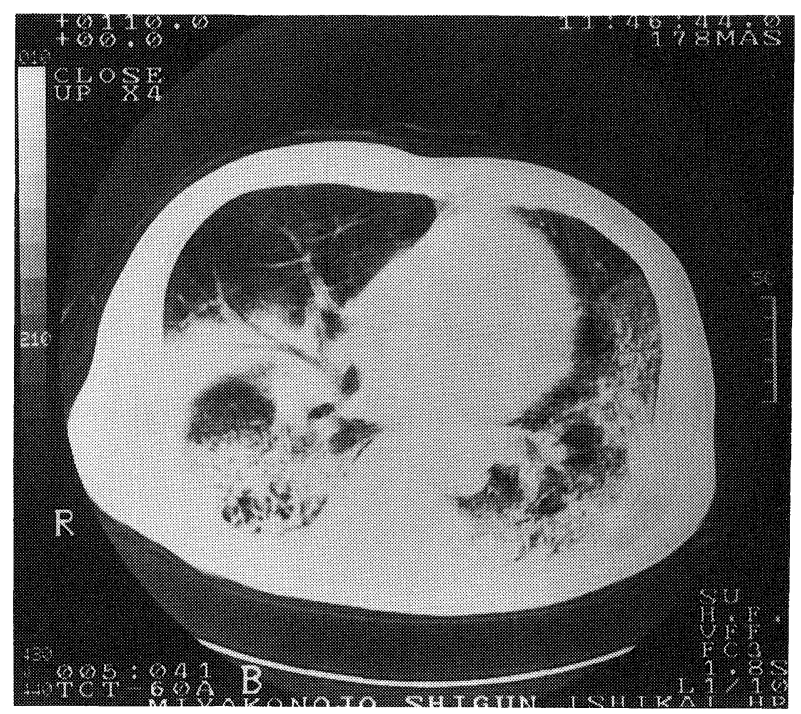

Figure 2. Computed tomography scans of chest on admission showing bilateral diffuse reticulonodular shadows and infiltrates in lung fields.

an increased percentage of neutrophils with no malignant cells, and an elevated level of SCC (Table 1). Direct examination of BALF with Gram, Ziehl-Neelsen and Grocott stains showed no microorganisms. Cultures of bronchial washings yielded no bacteria or fungal growth. Transbronchial lung biopsy was not performed because of the severe respiratory insufficiency.

The clinical course is summarized in Fig. 3. The diagnosis of ARDS was made based on the lung injury score of 2.5 (7), and ibuprofen, which was discontinued on admission, was sus- 


\section{SCC in ARDS}

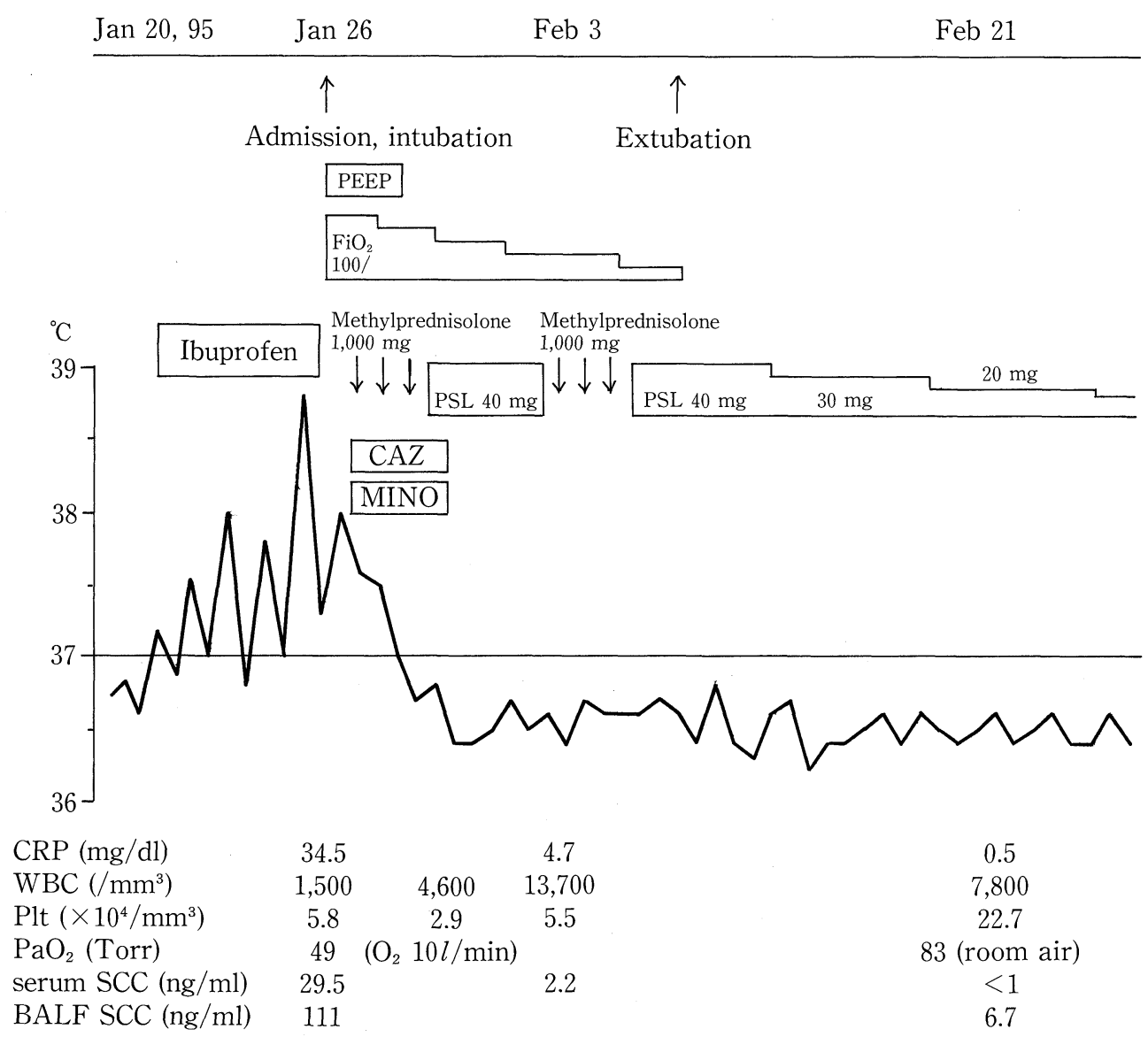

Figure 3. The clinical course.

pected to be the causative factor precipitating ARDS. Intravenous methylprednisolone therapy ( $1.0 \mathrm{~g} /$ day $)$ was begun on the first day of hospitalization and continued for three days. It was replaced with oral prednisolone $(40 \mathrm{mg} /$ day) for four days, but due to unsatisfactory clinical improvement, treatment was changed to methylprednisolone therapy $(1.0 \mathrm{~g} / \mathrm{day})$ for an additional three days. Thereafter, corticosteroid therapy was started with $40 \mathrm{mg} /$ day which was tapered gradually over a period of several weeks (Fig. 3). Clinical improvement was noted with dramatic reduction in serum SCC $(2.2 \mathrm{ng} / \mathrm{ml}$ on the seventh day after hospitalization, and $<1 \mathrm{ng} / \mathrm{ml}$ on the tenth day after hospitalization). Most of the diffuse shadows also disappeared (Fig. 4), and pancytopenia was corrected. On the thirtieth day of hospitalization, following marked clinical improvement, bronchoalveolar lavage was performed from the right $\mathrm{B}^{5}$. A sample of BALF showed almost normal cell classification (Table 1).

Blood and BALF levels of IL-8, neutrophil products and SCC in this patient are shown in Table 1. To compare these values with normal controls, we also measured the normal blood and BALF levels of neutrophil-related mediators and SCC in healthy volunteers (Table 1). The levels of SCC, IL-8, neutrophil elastase and defensins in BALF, IL-8 and SCC in serum, and neutrophil elastase and defensins in plasma, were all

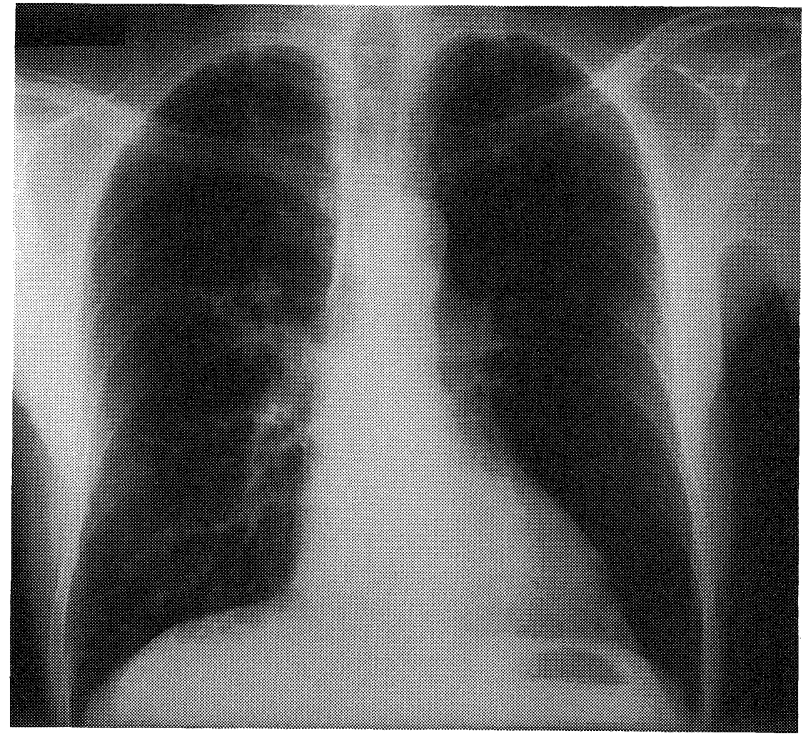

Figure 4. Chest roentgenogram on the thirtieth day of hospitalization showing disappearance of most of the diffuse shadows. 
increased on admission, compared with the mean levels of healthy volunteers.

IL-8 levels were measured with a sandwich enzyme-linked immunosorbent assay (Tore Fuji Bionix, Tokyo, Japan). Neutrophil elastase was measured by enzyme immunoassay (Sanwa, Nagoya, Japan). SCC (SCC • RIABEAD, Dainabot Co., Tokyo, Japan) and defensins (5) levels were measured by radioimmunoassay.

\section{Discussion}

In the present case of ARDS with increased serum and BALF levels of SCC, the diagnosis of ARDS was based on the lung injury score; it was most likely induced by ibuprofen based on the associated pancytopenia and weakly positive DLST. While peripheral blood neutropenia may occur in ARDS due to the accumulation of neutrophils in large numbers within the lung in the early stage of acute lung injury $(8,9)$, the pancytopenia observed in the present patient was suspected as a complication of ibuprofen therapy. However, the etiology of ARDS in this patient could not be identified as ibuprofen because pancytopenia also may appear in viral infection and DLST was not strongly positive. It has been suggested that circulating neutrophils play an important role in promoting the microvascular injury, characteristic of ARDS (10). It is also reported that the prognosis in ARDS is influenced by peripheral blood or BALF neutrophils and neutrophil elastase (1). Although the cause of ARDS is not yet known, it has been suggested that several factors may activate cytokines, such as IL-8, and subsequently form neutrophil products such as neutrophil elastase and defensins (11), which may contribute to lung damage (12). In fact, IL-8, neutrophil elastase and defensin levels in serum, plasma, and BALF were high in our patient before the initiation of therapy, compared with those after therapy or in healthy volunteers.

$\mathrm{SCC}$ is a protein appearing during the proliferating process of normal squamous epithelial cells. It has been used as a tumor marker for squamous cell carcinoma in certain organs (13). High serum levels of SCC are sometimes demonstrated in patients with non-malignant disease such as sepsis, eruption (2) and pulmonary infiltration with eosinophilia (3), while the level in benign diseases is usually less than $5.0 \mathrm{ng} / \mathrm{ml}$ by radioimmunoassay $(14,15)$. The serum level of SCC in the present case was as high as $29.5 \mathrm{ng} / \mathrm{ml}$, although no malignancy was present. More interestingly, the serum levels decreased to the normal range within only on week of treatment preceding clinical improvement. Thus, the serum level of SCC which probably derived from the lungs was parallel to the disease activity in this ARDS patient.

Our data of the detectable levels of SCC in BALF of healthy volunteers (Table 1) indicate a persistent production and release of SCC antigen in normal lungs. Perhaps, it may be produced and released by epithelial cells in the lungs (4), the physiological role in the air space, however, remains to be elucidated. The mechanisms of the elevated serum and BALF levels of SCC in our case were probably due to the accelerated production and release of SCC by epithelial cells. In this context, mononuclear cell-related cytokines, such as TNF $\alpha$, which can stimulate the release of SCC antigen from normal squamous epithelium (4), have been shown to be increased in BALF of ARDS patients (16). In fact, a high serum level of SCC is reported in sarcoidosis, which is closely associated with activation of mononuclear cells (17).

In conclusion, we reported increased serum and BALF levels of SCC in a patient with ARDS which was probably induced by ibuprofen. To our knowledge, this is the first report demonstrating an association between SCC and ARDS. Further investigation is needed to clarify whether SCC may be a useful marker for disease activity in ARDS.

\section{References}

1) Idell $\mathrm{S}$, Kucich U, Fein $\mathrm{A}$, et al. Neutrophil Elastase-Releasing Factors in Bronchoalveolar Lavage from Patients with Adult Respiratory Distress Syndrome. Am Rev Respir Dis 132: 1098, 1985.

2) Numahara $T$, Nakashima $K$, Yamamoto $S$, Nishimoto $M$. Significance of squamous cell carcinoma-related antigen in psoriasis and generalized eczema. Preliminary report. Dermatologica 178: 73, 1989.

3) Sakito O, Kadota J, Kohno S, Itho N, Takahara O, Hara K. Pulmonary infiltration with eosinophilia and increased serum levels of squamous cell carcinoma-related antigen and neuron specific enolase. Intern Med 33: $550,1994$.

4) Nakamura K. Stimulation of squamous cell carcinoma antigen production by tumor necrosis factor- $\alpha$ in human squamous cell carcinoma cells. Yamaguchi Igaku 40: 623, 1991 (in Japanese).

5) Shiomi K, Nakazato M, Ihi T, Kangawa K, Matsuo H, Matsukura S. Establishment of radioimmunoassay for human neutrophil peptides and their increases in plasma and neutrophil in infection. Biochem Biophys Res Commun 195: 1336, 1993.

6) Mukae H, Hirota M, Kohno S, et al. Elevation of tumor-associated carbohydrate antigens in patients with diffuse panbronchiolitis. Am Rev Respir Dis 148: 744, 1993.

7) Murray JF, Matthay MA, Luce JM, Flick MR. An expanded definition of the adult respiratory distress syndrome. Am Rev Respir Dis 138: 720, 1988 (published erratum appeared in Am Rev Respir Dis 139: 1065, 1989).

8) Bachofen M, Weibel ER. Alteration of the gas exchange apparatus in adult respiratory insufficiency associated with septicemia. Am Rev Respir Dis 116: 589, 1977.

9) Weiland JE, Davis WB, Holter JF, Mohammed JR, Dorinsky PM, Gadek JE. Lung neutrophils in the adult respiratory distress syndrome. Clinical and pathophysiologic significance. Am Rev Respir Dis 133: 218, 1986.

10) Tate RM, Repine JE. Neutrophils and the adult respiratory distress syndrome. Am Rev Respir Dis 128: 552, 1983.

11) Lichtenstein A. Mechanism of mammalian cell lysis mediated by peptide defensins. Evidence for an initial alteration of the plasma membrane. J Clin Invest 88: 93, 1991.

12) MillerEJ, Cohen AB, Nagao S, et al. Elevated levels of NAP-1/interleukin8 are present in the airspaces of patients with the adult respiratory distress syndrome and are associated with increased mortality. Am Rev Respir Dis 146: 427, 1992.

13) Sanchez De Cos J, Masa F, de la Cruz JL, Disdier C, Vergara C. Squamous cell carcinoma antigen ( $\mathrm{SCC} \mathrm{Ag}$ ) in the diagnosis and prognosis of lung cancer. Chest 105: 773, 1994.

14) Katsuragi M, Ichiya $Y$, Kuwabara $Y$, et al. Basic and clinical evaluation of squamous cell carcinoma related antigen (SCC) RIA kit. Kaku Igaku 22: 1809, 1985.

15) Kato H. TA-4 (SCC antigen). Rinsho Kensa 31(4): 430, 1987 (in Japanese).

16) Suter PM, Suter S, Girardin E, Roux-Lombard P, Grau GE, Dayer JM. 


\section{SCC in ARDS}

High bronchoalveolar levels of tumor necrosis factor and its inhibitors, interleukin-1, interferon, and elastase, in patients with adult respiratory distress syndrome after trauma, shock, or sepsis. Am Rev Respir Dis 145; 1016, 1992.
17) Bando M, Tani K, Kohrai F, Sano T, Kitamura S. A case of sarcoidosis with elevated SCC antigen in the serum and bronchoalveolar lavage fluid which was difficult to distinguish from lung cancer. Nippon Kyobu Sikkan Gakkai Zasshi 32: 95, 1994 (in Japanese). 